\title{
Observational responses of stratospheric sudden warming to blocking highs and its feedbacks on the troposphere
}

\author{
LU ChunHui* \& DING YiHui \\ National Climate Center, China Meteorological Administration, Beijing 100081, China
}

Received July 5, 2012; accepted September 4, 2012; published online November 5, 2012

\begin{abstract}
The influences of tropospheric blocking high on the stratospheric sudden warming (SSW) and the SSW-induced feedback on the lower atmosphere are analyzed with NCEP (National Center for Environmental Prediction) 2 reanalysis data. Daily mean data from 1979 to 2010 are used to perform statistical and dynamical analyses. According to different distribution features of polar vortex, which can be ascribed to different activities of blocking highs, we have obtained two warming patterns in vortex splitting and displacement patterns. For vortex splitting events, in the Eurasian-North American (ENA) paratype, with disturbances of Atlantic and Aleutian blocking highs, polar vortex is split into two parts that locate at Eurasian and North American continents respectively, while in the Atlantic-East Asian (AEA) paratype, two low-pressure centers derived from the split vortex are situated in the Atlantic and East Asian regions, and two blocking systems occurring in the Urals and North American areas precede these splitting processes. For vortex displacement events, in the Aleutian-Intrusion (AI) paratype, the polar vortex is displaced to the west European and Atlantic areas by the intrusive Aleutian high and this pattern always corresponds to the blocking events occurring in the Pacific basin only. Similarly, the vortex is pushed to the west Eurasian continent by the intrusive North American high-pressure system in the North American-Intrusion (NAI) paratype, which is closely related to the blocking over these areas. The second subject of the research is that whether the anomalous stratospheric signals can be propagated to the lower atmosphere, which is depended on the intensity, duration and position of the disturbed vortex. According to our case studies, geopotential height anomalies can be propagated to the troposphere in strong SSW years, taking about 10-15 d for the decrease from 10 to 500 $\mathrm{hPa}$, leading to apparent variations in the geopotential height and temperature fields.
\end{abstract}

stratospheric sudden warming, blocking high, polar vortex, stratospheric feedback, tropospheric anomalies

Citation: $\quad$ Lu C H, Ding Y H. Observational responses of stratospheric sudden warming to blocking highs and its feedbacks on the troposphere. Chin Sci Bull, 2013, 58: 1374-1384, doi: 10.1007/s11434-012-5505-4

Stratospheric Sudden Warming (SSW) events are the most remarkable phenomenon in the extratropical stratosphere in winter for the Northern Hemisphere [1,2]. Since 1971, Matsuno [3] proposed the mechanism of SSW, in which he assumed an impulsive intensification of planetary waves (PWs) triggered wave-induced deceleration of the polar westerly jet. A series of recent studies about SSW in terms of both observations and model simulations further indicate that SSW is a coupled dynamical process from the troposphere to stratosphere [4-6]. On the other hand, blocking high events are also major atmospheric flow phenomenon whose amplitude can disrupt the prevailing westerly cir-

*Corresponding author (email: alex61704@163.com) cumpolar circulation. They have a strong impact on the weather patterns and climatological features. Andrews et al. assumed that large-scale tropospheric disturbance, such as blocking high, may contribute to the SSW events for its long-lasting, strong and quasi-stationary disruptions to the tropospheric flow [1].

However, relationships between SSW and blocking events are yet to be firmly confirmed. The conventional idea indicated that blocking events were potential agents for reinforcement of PWs in the troposphere which may induce SSW events [1,2]. Lots of documented case studies on individual events also confirmed this link: Julian and Labitzke found that tropospheric blocking in high latitude preceded the warming events which happened in January 1963 by 
5-10 d [7]; Quiroz [8] compared blocking activity and SSW events from 1981 to 1985 , concluding that blocking events mostly lead SSW by $3.5 \mathrm{~d}$ on average; Mukougawa et al. [9] used operational weather forecasts results and analysis data (observations) to discuss associations between the mean zonal wind profiles and blocking high over the Atlantic basin in the December 2001 warming events, indicating that their interaction is significant for enhancing upward and poleward propagation of PWs before the SSW. On the other hand, there are also some researches denoting that SSW events precede blocking events. Kodera and Chiba [10] and Mukougawa and Hirooka [11] pointed out that in December 1984/January 1985 and in December 1998, there was a blocking formation after SSW events in relation to poleward propagation of PWs in the troposphere. Thompson and Wallace suggested that this tendency for blocking events to follow the SSW may correspond to the negative phase of AO, in which blocking days occurred more frequently [12].

The above mentioned different conclusions about the relationship between SSW events and blocking high may arise from two reasons: (1) Their analyses are limited to case studies, therefore it is unclear that these results can represent all SSW events; and (2) the methods used to identify blocking high are different in the above researches and still under debate. In addition, SSW is an event and blocking high is a synoptic system, thus it is unsuitable to associate them directly. Therefore, our study chose the stratospheric polar vortex as the representation of SSW, for its variations are able to reflect the warming processes [13]. By comparing the active characteristics of these two systems, it is much easier and more direct to obtain the possible associations between them two. For a pre-SSW period, we focused on the position and duration of blocking system that may disturb the polar vortex to induce a sudden warming, while for a post-SSW period, we mainly explored the downward propagation of SSW-induced anomalies.

\section{Data and analyses}

Reanalysis data from the NCEP (National Centers for Environmental Prediction) Reanalysis 2 Project are used to analyze the influences of blocking high on SSW events and the stratospheric feedback on the lower atmosphere. The NCEP2 reanalysis has 17 levels vertically, with the top level at $10 \mathrm{hPa}$ and $\mathrm{T} 159$ spectral resolution. In this study, a $144^{\circ} \times 73^{\circ}$ (longitude vs. latitude) grid of daily mean data from January 1, 1979 to December 31, 2010 were used. To characterize the timing and intensity of a SSW event, the warming criteria established by WMO was chosen. This criteria is composed by two components, the meridional temperature gradient $(\Delta t)$ and zonal mean zonal wind $(\bar{u})$ between $60^{\circ} \mathrm{N}$ and pole on the $10 \mathrm{hPa}$ level. In this investigation, we only focus on the major warming event, which mean that the westerly winds reverse and become easterly $(\bar{u}<0)$. Based on these criteria, 21 sample cases occurred during these 32 years.

The blocking high is a sustained, vertically coherent and quasi-stationary large-scale high-pressure system in extratropical areas, and there is no generally accepted objective definition yet. Some early studies used the $500 \mathrm{hPa}$ geopotential height $(\mathrm{GH})$ as the block indices, which were based upon the determination of major positive height anomalies $[14,15]$, a localized positive latitudinal gradient of the geopotential field [16] and so on. Recently, based on the potential vorticity (PV) theory, Schwierz et al. [17] proposed a new indicator which defined a block as a persisted and significant quasi-isolated feature of low PV and/or a negative PV anomaly. In this research, for every SSW event we analyzed the activity characteristics of blocking high using the three indices mentioned above, and found that the blocking high was closely connected to the disturbance of stratospheric polar vortex from all the three points of view. Because the target of this study is to expose more detailed relationship between the block and SSW event, and obtain the statistically significant results. We finally provided the composite distribution of geopotential height and considered the $\Omega$-shaped distribution of $\mathrm{GH}$ as the atmospheric blocking. For this method of composite analyses, using GH or PV as the composite object has little differences.

During the 21 times of warming processes, the polar vortex exhibits different distribution features, which can be divided into vortex splitting (10 times) and displacement or eccentric (11 times) events. Moreover, after some further analyses, we found that different blocking activities would lead to more concrete distribution characteristics of the polar vortex, and SSW events can be classified further into four paratypes accordingly. From vortex splitting events, two patterns are obtained: Eurasian-North American (ENA), which denotes that the two low-pressure centers came from the split vortex locate at the Eurasian and North American continents respectively (Figure 1(c)); Atlantic-East Asian (AEA), meaning that the two centers occur in the Atlantic basin and East Asian regions separately (Figure 1(f)). Similarly, from vortex displacement events, we also found two patterns: Aleutian-Intrusion (AI), which means the vortex is displaced to the west European and Atlantic areas by the intrusive Aleutian high; North American-Intrusion (NAI), implying that the high-pressure system from west parts of North America intrudes into polar regions and pushes the vortex to the west Eurasian continent. Table 1 shows a list of all events, which includes the central date of each SSW event, the geographic location of tropospheric blocking and the warming patterns. To perform composite analyses, we defined the central date of every event, day 0 in all the composites, as the date when the polar vortex starts to split or the zonal wind $(\bar{u})$ begins to be negative in vortex splitting or displacement events respectively. The composite analysis is carried out for the time period -10 to $10 \mathrm{~d}$ and the statistical significance of the composites with respect 
(a) Day $=-4$

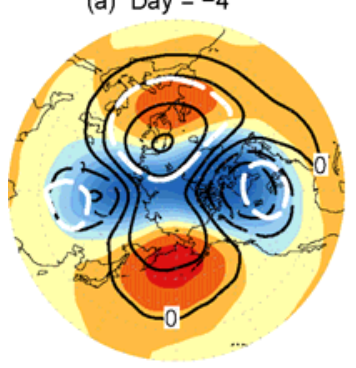

(d) Day $=-4$

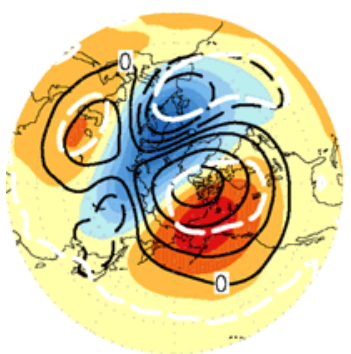

(b) Day $=-2$

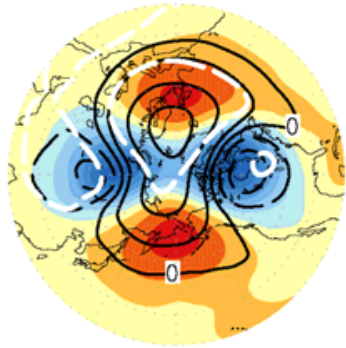

(e) Day $=-2$

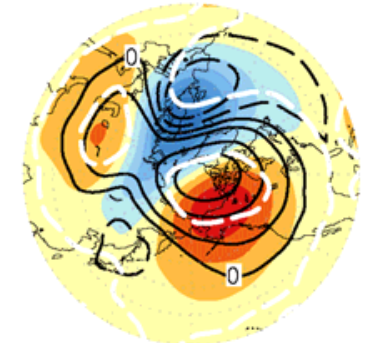

(c) Day $=0$

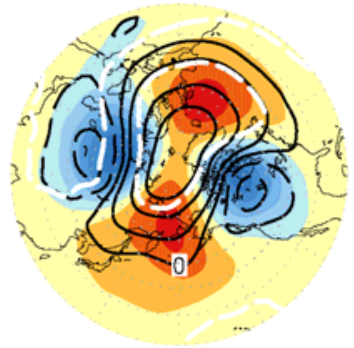

(f) Day $=0$

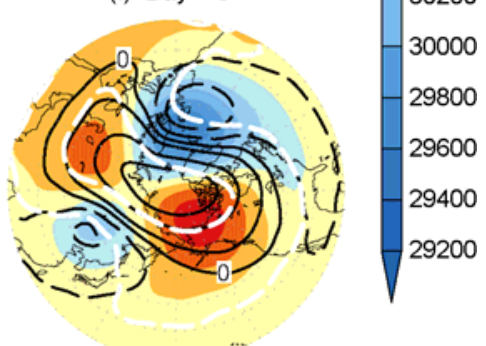

Figure 1 Composite distributions of geopotential height (color scale, unit: gpm) and its anomalies (black contour lines, unit: gpm) on 10 hPa before the vortex splitting day. Areas within white contour lines indicate statistically significant anomalies at $95 \%$ confidence level.

Table 1 Geographic location of tropospheric blocking prior to the central date of the corresponding stratospheric sudden warming events

\begin{tabular}{|c|c|c|c|c|c|}
\hline \multicolumn{3}{|c|}{ Vortex displacement events } & \multicolumn{3}{|c|}{ Vortex splitting events } \\
\hline Central date & Pattern & Precursor blocking & Central date & Pattern & Precursor blocking \\
\hline $1984-02-21$ & NAI & West North America & $1984-12-30$ & ENA & Pacific/east Atlantic \\
\hline $1987-01-22$ & NAI & West North America & $1987-12-12$ & Special & Pacific \\
\hline 1988-03-11 & NAI & West North America & $1998-12-19$ & Special & West North America \\
\hline $1991-02-03$ & AI & Aleutian Island & $1999-02-27$ & AEA & North America/Urals \\
\hline 1993-03-05 & NAI & West North America & 2004-01-12 & AEA & North America/Urals \\
\hline $1995-02-02$ & NAI & West North America & $2005-03-12$ & AEA & North America/Urals \\
\hline $2002-02-16$ & NAI & West North America & 2006-02-04 & AEA & North America/Urals \\
\hline 2003-01-17 & AI & Aleutian Island & $2009-01-25$ & ENA & Pacific/east Atlantic \\
\hline $2007-02-22$ & AI & Aleutian Island & 2010-02-04 & AEA & North America/Urals \\
\hline $2008-02-22$ & AI & Aleutian Island & & & \\
\hline
\end{tabular}

to a climatological state is examined using the Student $t$-test, consistent with that used in the paper of Lu et al. [18].

\section{Vortex splitting events}

In light of the above analyses, we have found that different warming patterns correspond to different locations and intensities of tropospheric blockings, and may result in diversified feedbacks on the lower atmosphere. First, for the ENA pattern, Figure 1(a)-(c) shows the composite distributions of geopotential height (shaded parts) on $10 \mathrm{hPa}$ before the polar vortex split. The black contour lines indicate the anomalies comparing with the climatology and statistically significant anomalies at the $95 \%$ confident level, according to Student's $t$-test, are encircled by white dashed lines. As shown in this figure, the polar vortex was disturbed by two high-pressure systems, located at the Aleutian areas and east Atlantic basin. These two centers developed and strengthened respectively after their appearing about one week before the vortex split. They expanded gradually to the polar areas and when they were connected to each other, the polar vortex was divided into two parts, which were situated at the Eurasian and North American continents. Comparing with the climatology, the major anomalies took place in arctic regions, where the positive anomalies reached approximately $900 \mathrm{gpm}$ on day 0 and most of the strong anomalous regions exceeded the $95 \%$ confidence level. This positive center grew up gradually from the early period of stratospheric warming and corresponded closely to the two high-pressure systems, denoting that during the entire warming processes the polar vortex was disturbed and 
weakened step by step until collapsed on day 0 . Based on the above analyses, the variations of ENA sudden warming pattern can be attributed to the activities of Aleutian and east Atlantic high-pressure systems in the stratosphere.

To find out more relationship between the stratospheric high-pressure system and the tropospheric blockings, composite distribution of geopotential height at 500 and $100 \mathrm{hPa}$ levels on $-4,-2$ and $0 \mathrm{~d}$ are shown in Figure 2. The grey-scale indicates the statistical significance of composites at the $90 \%$ and $95 \%$ confidence levels. As indicated on the $500 \mathrm{hPa}$ level, there were two apparent blocking highs locating at the east Pacific basin (about $150^{\circ} \mathrm{W}$ ) and the Urals regions (about $60^{\circ} \mathrm{E}$ ) on $-4 \mathrm{~d}$. With the development of warming processes, these two blocks expanded northward and westward strongly. On $-2 \mathrm{~d}$, the main blocking areas have reached to the Aleutian Islands and east Atlantic basin, with the significant intrusion into the Arctic regions. To the $0 \mathrm{~d}$, when the stratospheric vortex was splitting, a closed high-pressure system can be observed in the areas northwest to the Aleutian Islands, and meanwhile an obvious $\Omega$-shaped blocking pattern was occurring in the east Atlantic basin. These two blocking patterns had a good correspondence with the stratospheric high-pressure systems in terms of both the locations and intensities. In addition, we also found that the geographical extent of high statistical confidence was mostly distributed in the regions where the geopotential height fields have great deformation, such as the blocking high and trough-line areas. This suggests that there are apparent disturbances in the tropospheric circulation before the stratospheric vortex splitting, and the blocking activity characteristics are of typical statistical significance.
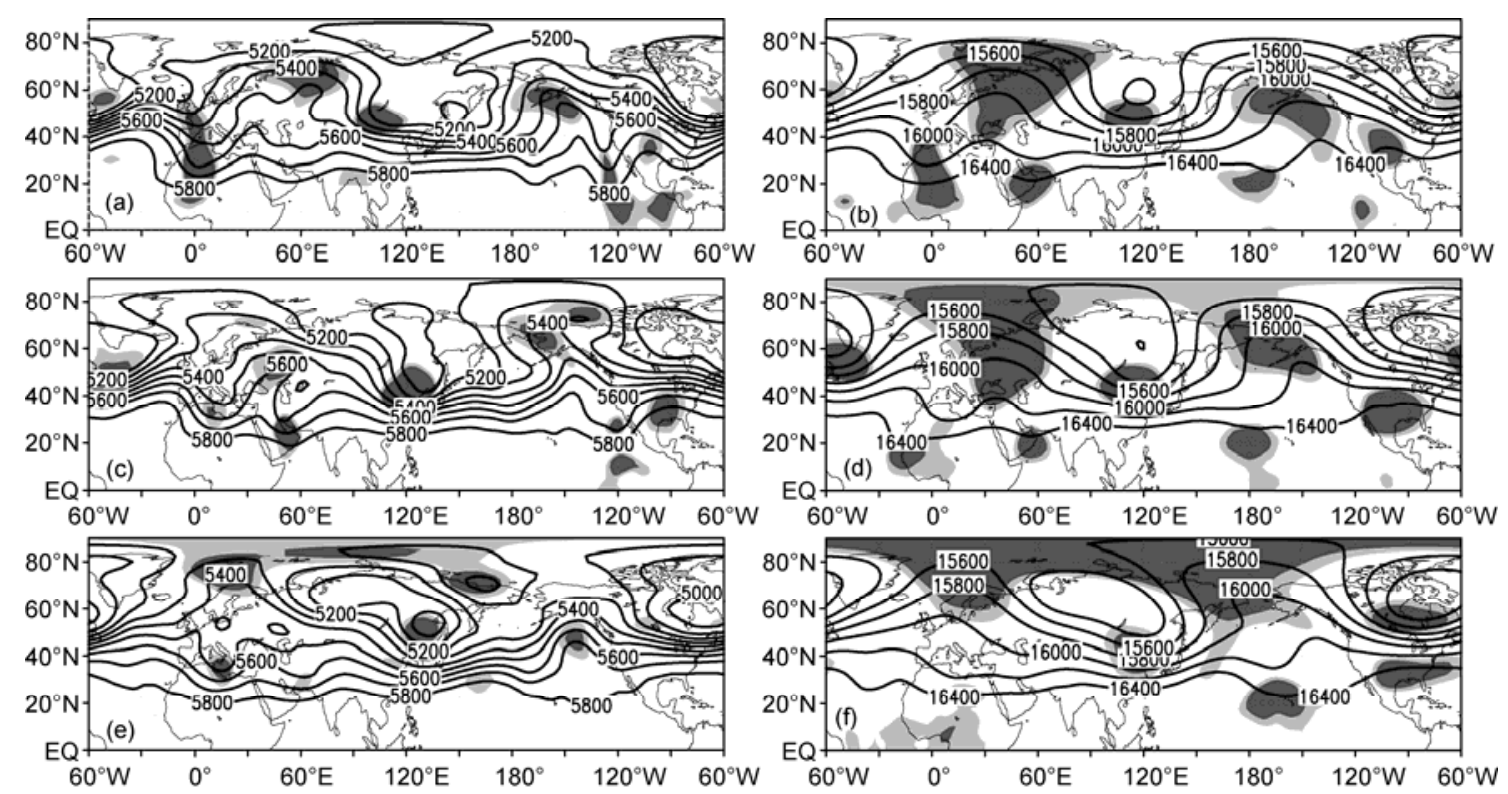

Figure 2 In the ENA pattern, composite distributions of geopotential height (unit: gpm) on $500 \mathrm{hPa}$ and $100 \mathrm{hPa}$ before the vortex splitting day. (a) and (b) Day $=-4$; (c) and (d) day=-2; (e) and (f) day=0. (a), (c) and (e) $500 \mathrm{hPa}$; (b), (d) and (f) $100 \mathrm{hPa}$. The greyscale indicates statistically significant anomalies at the $90 \%$ (light grey) and $95 \%$ (dark grey) confidence levels. 
the values of the positive center. Moreover, all of the significant anomalous areas exceeded the 95\% statistical confidence level. According to the analyses mentioned above, we can conclude that the Urals and North American highpressure systems play an important role in the AEA pattern of SSW events.

Composite distributions of geopotential height at $500 \mathrm{hPa}$ and $100 \mathrm{hPa}$ levels on $-4,-2$ and $0 \mathrm{~d}$, as shown in Figure 3, illustrated the relationship between the blocking high and the stratospheric high-pressure system, which is significant in the AEA pattern. On the $500 \mathrm{hPa}$ level, two evident blocking patterns were found in the Urals (around $60^{\circ} \mathrm{E}$ ) and west parts of North America $\left(150^{\circ}-120^{\circ} \mathrm{W}\right)$ during a period one week before the vortex split. The Urals blocking occupied a wide longitudinal range from $30^{\circ} \mathrm{E}$ to $120^{\circ} \mathrm{E}$ with the movement along latitude, and finally expanded northward into the Arctic regions on $0 \mathrm{~d}$, while the North American blocking was relatively stationary and only developed northward to affect the high latitude areas. On the other hand, on $100 \mathrm{hPa}$ level the North American blocking pattern was clearly observed in all the three days, indicating its coherent vertical structure, while the Urals blocking was not as apparent as that in troposphere, corresponding to the weaker high-pressure center on $10 \mathrm{hPa}$. Above analyses suggest that the influences of blocking high on the stratosphere depend on not only the intensity of the blocking itself, but also on the effective height the blocking can reach. Thus, not every blocking event will affect the middle and high atmosphere. In addition, there is another way of highpressure systems aroused by the tropospheric blocking to disturb the vortex. For example, in winter of the 2005-2006, unlike the above situations, the Aleutian high moved westward instead of North American continent. Furthermore, the Urals high shifted eastward to connect with the Aleutian high, and then this new re-formative high-pressure center expanded poleward, splitting the polar vortex. Consequently, the above investigations indicate that the AEA warming pattern can be attributed to the Urals and North American highs, which are always preceded by blocking events occurring in these two places.

\section{Vortex displacement events}

Composite distributions of geopotential height (shaded parts) and its anomalies (black contours) on $10 \mathrm{hPa}$ are shown in Figure 4(a)-(c) to investigate the Aleutian-Intrusion pattern of SSW events. As shown in this figure, polar vortex was disturbed by only one high-pressure system located at the Aleutian Islands, which is different from the vortex splitting events. This is also the reason that the vortex is just displaced rather than split in the whole warming processes. The Aleutian high developed and reinforced gradually since its emergence in the early period. To the $0 \mathrm{~d}$, the vortex was displaced to the west parts of Eurasian continent and Atlantic basin by the high-pressure center. Most anomalous geopotential height took place in the high latitudes regions, which is closely related to Aleutian high. The positive anomalies can reach about $600 \mathrm{gpm}$ before the major warming $(\bar{u}<0)$ and most of the strong anomalous areas exceeded the $95 \%$ confidence level. According to the above analyses, the AI pattern warming events can be ascribed as the disturbances of the polar vortex caused by the Aleutian high and this high-pressure system is the most significant and only influencing factor during the warming processes.

Furthermore, Figure 5 illustrates the composite distributions of geopotential height on 500 and $100 \mathrm{hPa}$ levels before the central time $(0 \mathrm{~d})$ to show the connections between the
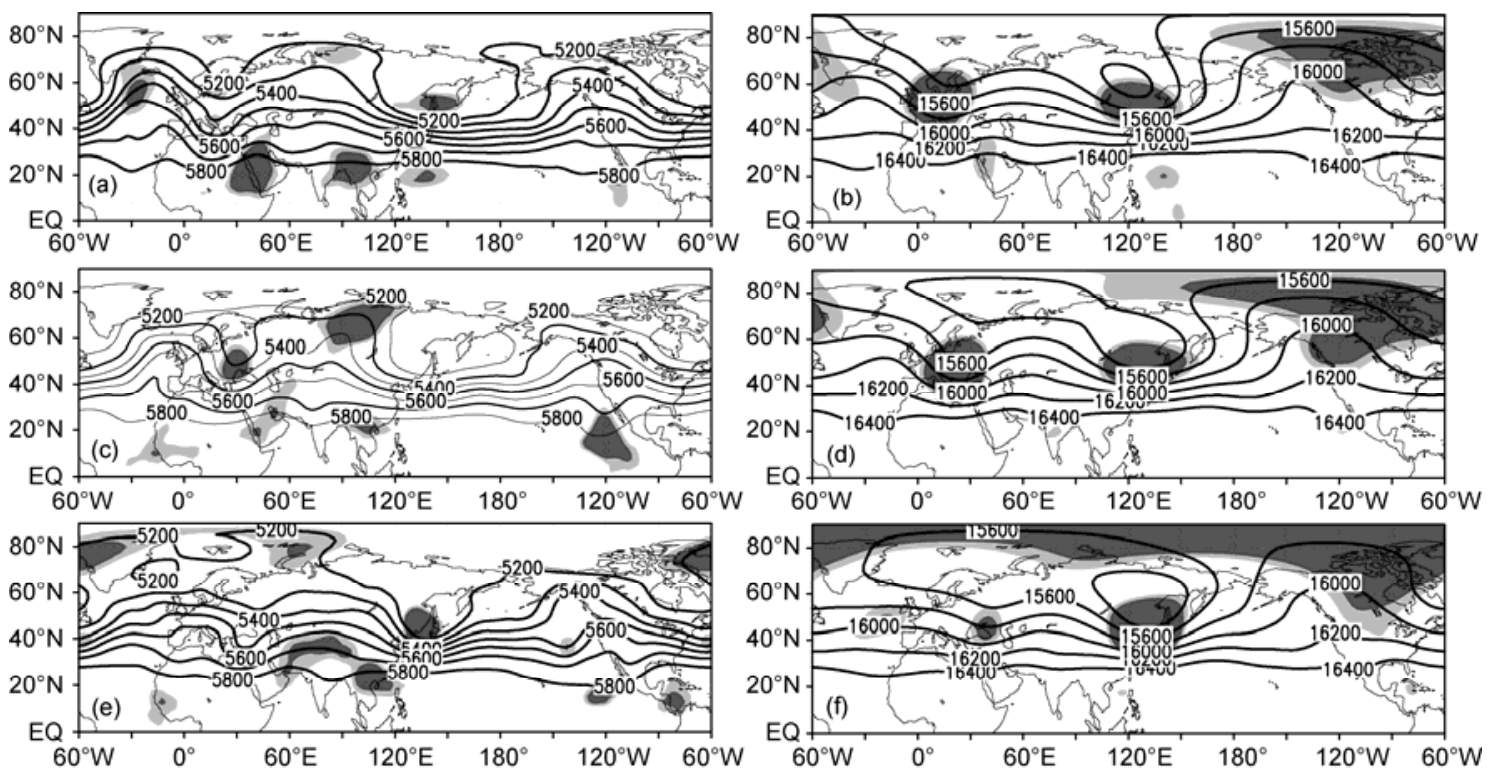

Figure 3 Same as in Figure 2, but for the AEA pattern. 
(a) Day $=-4$

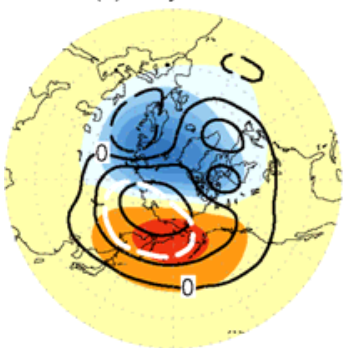

(d) Day $=-4$

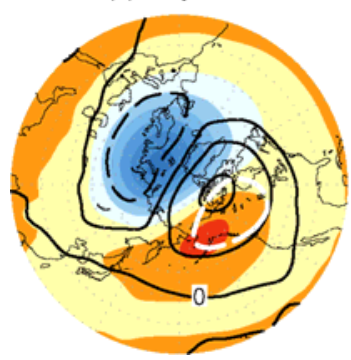

(b) Day $=-2$

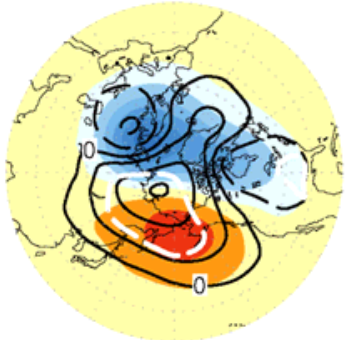

(e) Day $=-2$

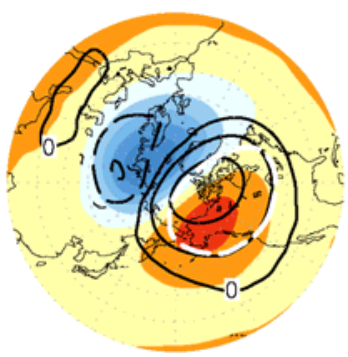

(c) Day $=0$

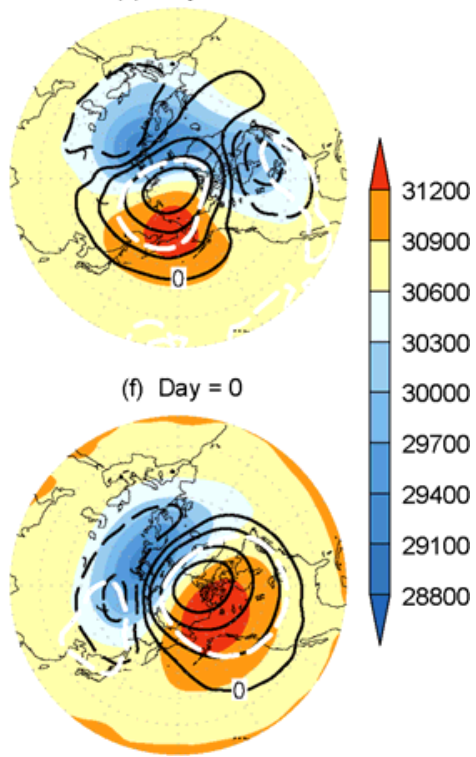

Figure 4 Composite distributions of geopotential height (color scale, unit: gpm) and its anomalies (black contour lines, unit: gpm) on 10 hPa before the warming central day. Areas within white contour lines indicate statistically significant anomalies at $95 \%$ confidence level.
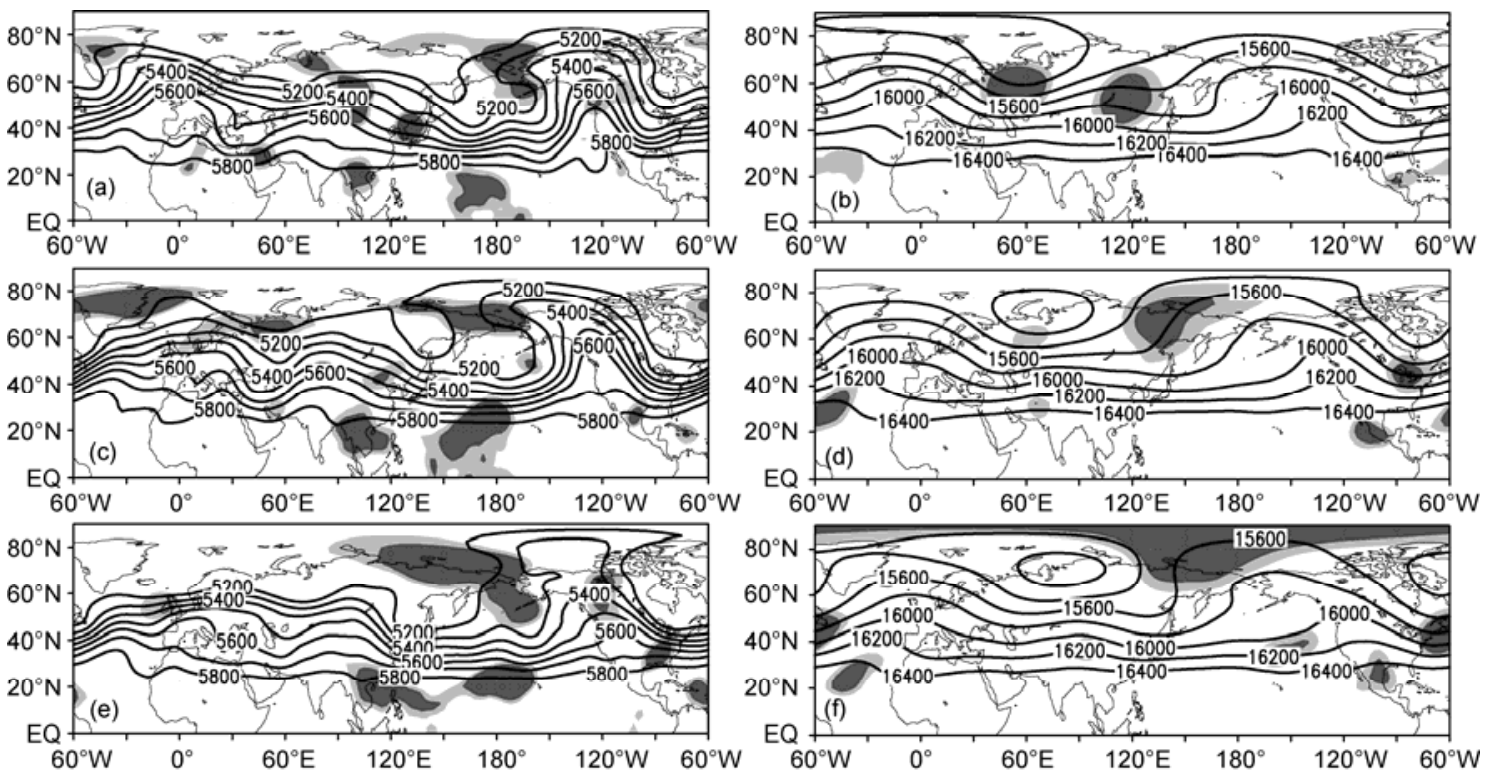

Figure 5 In the AI pattern, composite distributions of geopotential height (unit: gpm) on $500 \mathrm{hPa}$ and $100 \mathrm{hPa}$ before the vortex splitting day. (a) and (b) Day $=-4$; (c) and (d) day=-2; (e) and (f) day=0. (a), (c) and (e) $500 \mathrm{hPa}$; (b), (d) and (f) $100 \mathrm{hPa}$. The greyscale indicates statistically significant anomalies at the $90 \%$ (light grey) and $95 \%$ (dark grey) confidence levels.

tropospheric blocking and stratospheric Aleutian high, the critical contributor in the AI pattern. First, on the $500 \mathrm{hPa}$ level, there was an evident blocking system located at the west coast of North American continent, and along with the increase of warming intensity the blocking expanded westward and northward, intruding into the polar areas from Aleutian Islands in the end. The major areas exceeding the statistical confidence level also located at the Aleutian regions, indicating the appearance of blocking anomalies. On the $100 \mathrm{hPa}$ level, the geopotential height filed had a similar distribution to that on $500 \mathrm{hPa}$. Apparent blocking system was observed at about $180^{\circ}$ and its outstanding statistical parts were found at the Aleutian Islands too. This coherent vertical structure denotes that this blocking system, located at the Aleutian areas, is the major contributor to the stratospheric high-pressure system that playing a significant role in the AI warming pattern.

For the North American-Intrusion pattern of SSW events, similar distributions of composite geopotential height and its anomalies on $10 \mathrm{hPa}$ before the central time are dis- 
played in Figure 4(d)-(f). As shown in these figures, there was also only one high-pressure system disturbing the polar vortex, which is located at the west parts of North American continent. This high-pressure center, derived from the Aleutian high, reinforced and developed eastward and poleward gradually leading to the deviation of polar vortex that displaced to the east Atlantic basin and west Eurasian continent. The distribution of GH anomalies was closely related to the high-pressure system in terms of both the position of major positive center and the regions where the significant anomalies exceeded the 95\% confidence level. Consequently, above analyses suggest that the NAI warming pattern can be ascribed to the activities of North American high-pressure system and the system is the only effective contributor during the whole period.

Composite distributions of geopotential height at 500 and $100 \mathrm{hPa}$ levels on $-4,-2$ and $0 \mathrm{~d}$, as shown in Figure 6, demonstrate the connections between the tropospheric blocking and the stratospheric high-pressure system, which is critical in the NAI warming pattern. On the $500 \mathrm{hPa}$, an apparent blocking pattern can be found in the west coast of North America (around $120^{\circ} \mathrm{W}$ ) in all the three days. This blocking system occurred in the early period of warming processes, about one week before the central time, and was relatively stationary in the longitudinal direction. It finally stretched poleward into the high latitude areas on 0 day to disturb the polar atmosphere. On the other hand, on $100 \mathrm{hPa}$ level, the North American blocking pattern was clearly observed in all the three days in terms of both the blocking structure and the regions exceeding $90 \%$ and $95 \%$ statistical confidence levels, proving that this blocking has a coherent vertical structure and is able to affect the stratosphere. On the basis of the above analyses, we can conclude that the NAI pattern of SSW events can be attributed to the strato- spheric North American high, which is preceded and supported by the tropospheric blocking occurred there $\left(90^{\circ}-\right.$ $\left.120^{\circ} \mathrm{W}\right)$.

\section{Feedback on the lower atmosphere}

Different influences of blocking high on the stratospheric circulations in SSW events were discussed above, indicating that variations of polar vortex always depended on the activities of blocking systems located at different regions. After these analyses we also investigated the feedback of anomalous stratospheric circulations on the lower atmosphere after warming events, and found that whether the stratospheric signals could propagate downward to the troposphere, depending on the intensity and duration of the disturbed vortex. If the vortex anomalies last more than one week, these anomalous signals can be observed in the lower levels, but if the disturbed vortex returns to normal shortly or changes its position frequently, the anomalies will concentrate in the stratosphere only, denoting that influences of the stratospheric anomalies on the troposphere were conditional. Therefore, four typical warming examples corresponding to the four paratypes of SSW events were selected to investigate the warming feedback: 2008-2009 winter for the ENA pattern, 2009-2010 winter for the AEA pattern, 2007-2008 winter for the AI pattern and 1986-1987 winter for the NAI pattern.

First for the ENA pattern, Figure 7(a) exhibits the longitude-vertical cross sections of GH anomalies along $60^{\circ} \mathrm{N}$ in 2008-2009 winter. In order to illustrate the downward propagation of stratospheric anomalies easily, on different vertical layers the anomalies occurring in different times were displayed. On the $10 \mathrm{hPa}$ level, anomalies on 0 day
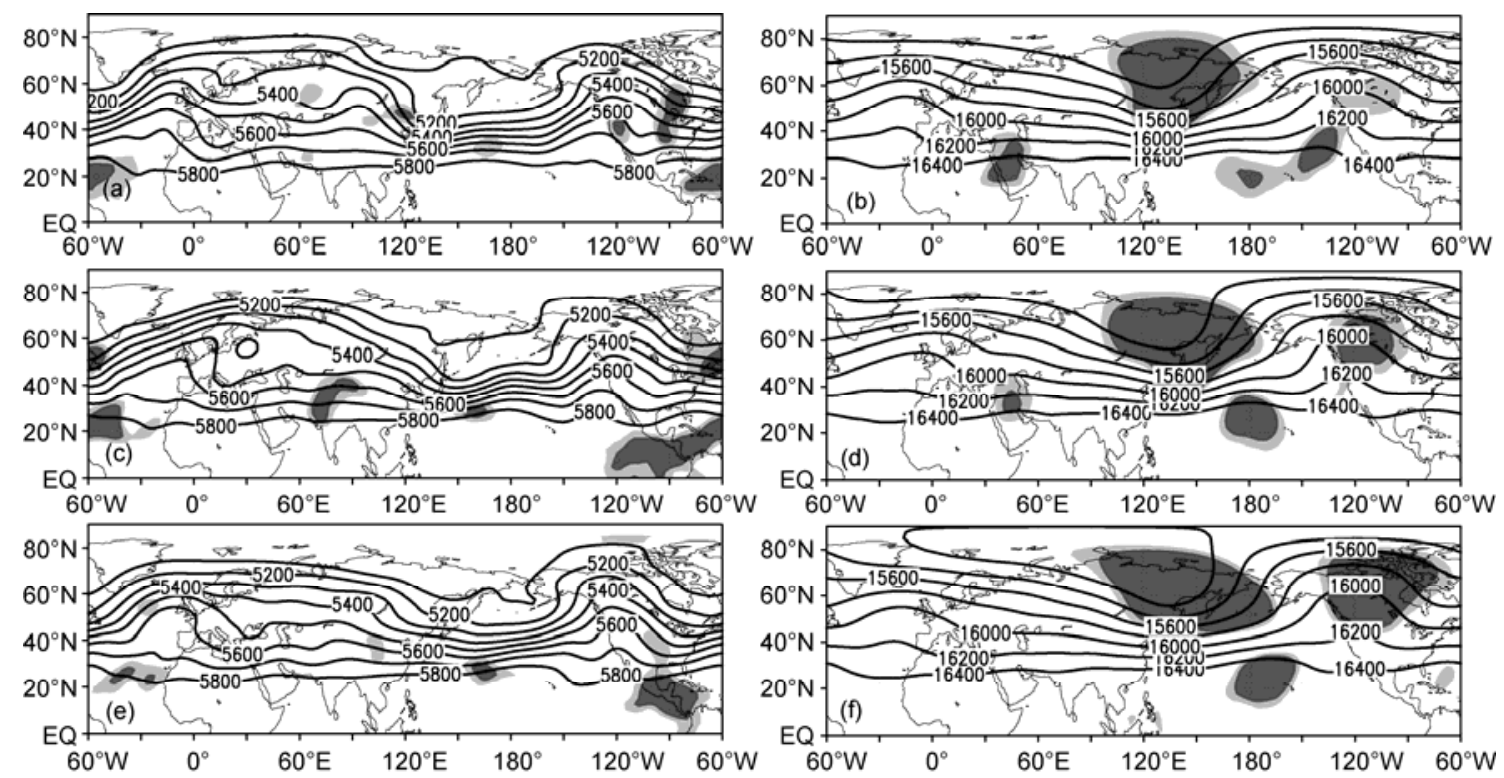

Figure 6 Same as in figure 5, but for the NAI pattern. 

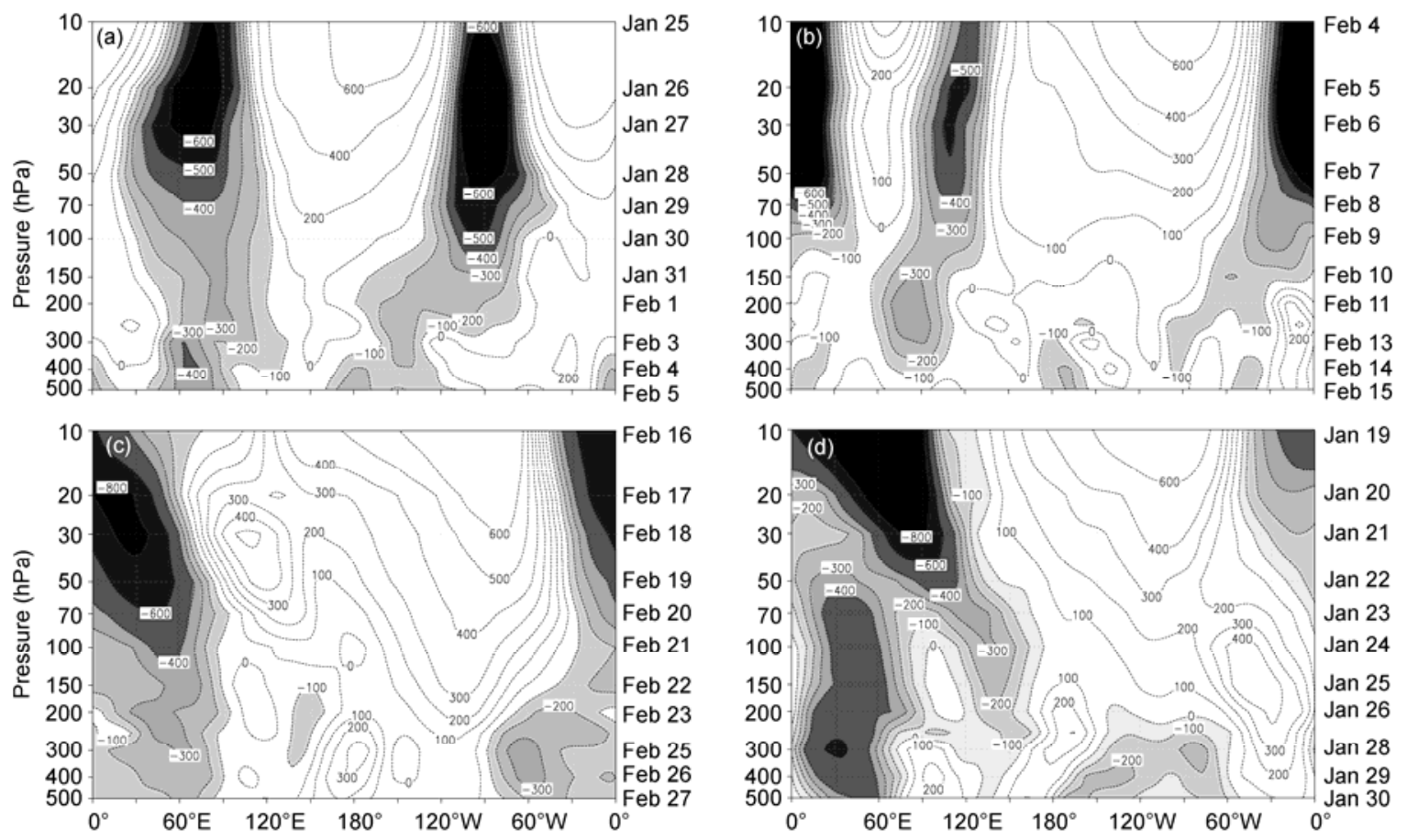

Figure 7 Height-longitude sections of geopotential height anomalies (unit: gpm) in (a) the ENA pattern (2008-2009 winter), (b) the AEA pattern (20092010 winter), (c) the AI pattern (2007-2008 winter) and (d) the NAI pattern (1986-1987 pattern).

(January 25, 2009) were shown and along with the decline of isobaric surface the time of chosen data were developed step by step. The right coordinate of Figure 7(a) marks the corresponding date of each layer. As shown in this figure, there were two apparent negative centers at the Eurasian and North American continents, consistent with the positions of the two stratospheric low-pressure centers derived from the splitting vortex. The largest centers of the Eurasian anomalies happened in the upper stratosphere (above 70 $\mathrm{hPa}$ ), reaching about $-600 \mathrm{gpm}$, and these negative anomalies propagated downward to the troposphere as time goes by. On February 5, evident anomalous GH was observed from $60^{\circ}-90^{\circ} \mathrm{E}$ on $500 \mathrm{hPa}$, implying the decrease of the Urals blocking high. The North American major negative centers occurred in the levels from 150 to $10 \mathrm{hPa}$, reaching about $-600 \mathrm{gpm}$ too. The anomalies propagated downward to the lower layers with some westward development from the $200 \mathrm{hPa}$ level, bringing some influences to the east $\mathrm{Pa}$ cific areas $\left(120^{\circ} \mathrm{W}-180^{\circ}\right)$ on $500 \mathrm{hPa}$. These two anomalous regions denoted that cold low-pressure centers, derived from the splitting vortex, expanded southward to the middle and high latitudes, bringing cooling anomalies there in Eurasian and North American continents. In order to illustrate this point clearly, Figure 8(a) shows the longitude-latitude cross sections of temperature (shaded parts) and GH (black contours) anomalies at $500 \mathrm{hPa}$ on February 5, 2009, and the areas encircled in thick dashed lines indicate the evident negative GH anomalies (less than $-100 \mathrm{gpm}$ ). As shown in this figure, cooling regions mostly corresponded to the strong negative $\mathrm{GH}$ anomalies, and were consistent with the areas where the stratospheric $\mathrm{GH}$ signals propagated to (Figure 7(a)). In the middle and high latitudes of Eurasian continent, negative GH and temperature anomalies dominated most of the areas west to $90^{\circ} \mathrm{E}$ with the largest $\mathrm{GH}$ center reaching about $-300 \mathrm{gpm}$, corresponding to 6-9 degrees cooling in the Urals and northwest parts of Europe. There were also negative anomalies of temperature and GH in the north Pacific, but with weaker intensity than those of Eurasian parts. Anomalous signals propagated from the stratosphere led to 3-6 degrees cooling in the North American Alaska areas, Aleutian Islands and east Siberia. Consequently, during the ENA warming events, if the splitting polar vortex can last more than one week, the cold low-pressure centers were able to influence downward to the tropospheric circulation and negative $\mathrm{GH}$ anomalies came from the stratosphere will induce apparent cooling in the Urals, northwest Europe and north Pacific regions.

Similar to Figure 7(a), longitude-vertical cross sections of GH anomalies in 2009-2010 winter are shown in Figure 7(b) to reveal the propagation features of stratospheric signals in the AEA pattern. As shown in this figure two evident negative centers were observed in the East Asian and Atlantic regions above $100 \mathrm{hPa}$, corresponding to the two parts of splitting vortex. The Atlantic anomalies were mainly concentrated in the stratospheric levels with largest center reaching about -600 gpm, and only its west parts had some downward and westward developments, being able to arrive at the upper troposphere, 200-300 hPa. On the other hand, the East Asian anomalies had two closed centers, which were located at the upper stratosphere and troposphere 


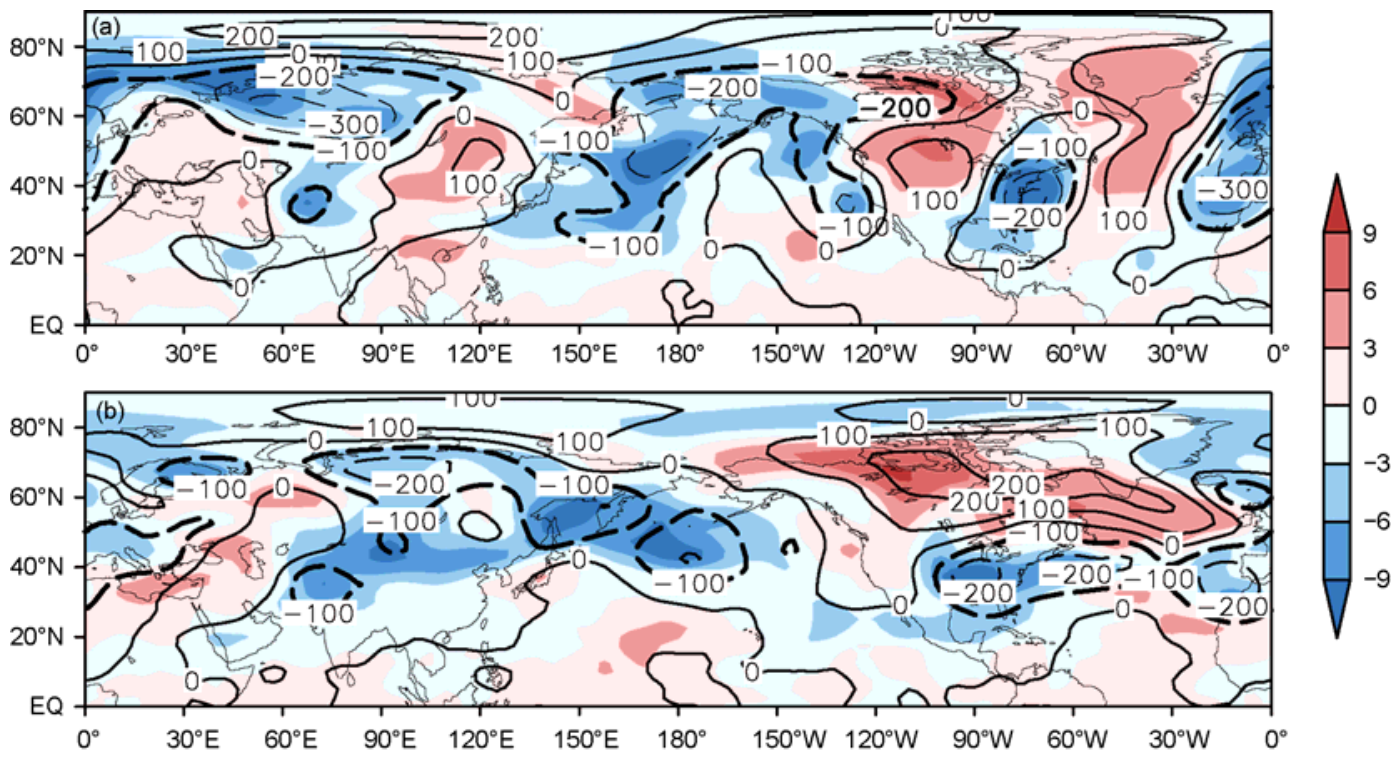

Figure 8 Distributions of temperature (shaded parts, unit: K) and geopotential height (black contours, unit: gpm) anomalies at $500 \mathrm{hPa}$ on (a) February 5 , 2009 and (b) February 15, 2010. The thick dashed line indicates $-100 \mathrm{gpm}$.

respectively, indicating the downward propagations of negative geopotential height signals. From the distributions of temperature and $\mathrm{GH}$ anomalies at $500 \mathrm{hPa}$ on February 15, 2010, as shown in Figure 8(b), we can find the evident negative $\mathrm{GH}$ anomalies in the middle and high latitudes of East Asia. From $90^{\circ} \mathrm{E}$ east to the Pacific basin, apparent cooling phenomena can be observed in these areas, and especially in the middle China and north Japan, cooling ranges reached about $6^{\circ}-9^{\circ}$. In the north Atlantic regions, there were also negative temperature anomalies, but with less cooling extent. This is because in these areas major GH signals, originated in the stratosphere, were concentrated in the upper layers above the troposphere, and their influences on the $500 \mathrm{hPa}$ circulation were weaker. In conclusion, during the AEA warming events, when the polar vortex split more than one week, negative $\mathrm{GH}$ anomalies can be propagated downward to the East Asia and Atlantic basin, where the two cold low-pressure systems located. Moreover, the downward influences were stronger in the East Asian regions, leading to apparent cooling effects in the middle China and north Japan. Comparing the above two patterns of vortex splitting events, we can draw a conclusion that the downward propagation regions and intensities of stratospheric anomalies were determined by the position and duration of the polar vortex splitting processes respectively. In 2008-2009 winter (ENA pattern) the splitting time of vortex lasted about $20 \mathrm{~d}$, while in 2009-2010 winter (AEA pattern) the vortex has been separated for approximately $10 \mathrm{~d}$. Therefore, the downward propagation signals were stronger in the ENA pattern year in terms of both the longitudinal range of negative geopotential height and the tropospheric levels which the signals can arrive at.

For the vortex displacement events, similar distributions of GH anomalies in the AI and NAI patterns were displayed in Figure 7(c) and (d) respectively. As shown in this figure, there was only one negative GH center in the stratosphere, and its position corresponded to the displaced polar vortex. Like the vortex splitting events, the position and duration of disturbed vortex determined the downward propagations of stratospheric anomalies. Therefore, in the AI warming pattern downward propagations mostly distributed in the northeast parts of North America, north Atlantic and northwest Europe, while in the NAI warming pattern, major negative $\mathrm{GH}$ anomalies were propagated down to the middle and west parts of Eurasian continent, resulting in some associated changes in the related atmospheric circulations.

\section{Discussions and conclusions}

We have analyzed the impact of tropospheric blocking high on the stratospheric sudden warming and its feedback on the lower atmosphere using the NCEP2 reanalysis data. We found that during SSW processes polar vortex had different distribution features, which were closely related to the activities of tropospheric blocking systems. Therefore, SSW events were classified into two patterns with four paratypes, based on the distributions of polar vortex and blocking high, and then different variation characteristics of these two systems were diagnosed and analyzed. The main conclusions are as follows.

During the SSW processes, the polar vortex was disturbed by one or two high-pressure systems. If there was only one high-pressure center, the vortex would be pushed out of the polar areas, but if there were two high-pressure centers, the vortex would be spitted as soon as the two high systems connected to each other. Furthermore, the stratospheric high-pressure system was closely coupled with the 
tropospheric blocking high in different warming patterns. From vortex splitting events, there were two warming patterns: Eurasian-North American (ENA) pattern, which meant the splitted two centers, derived from the split polar vortex, located at the Eurasian and North American continents respectively; Atlantic-East Asian (AEA) pattern meaning that the two vortex centers occurred in the Atlantic basin and East Asian regions separately. Based on the composite results, the ENA pattern was mostly always preceded by blocking high over the Pacific basin $\left(150^{\circ} \mathrm{W}-180^{\circ}\right)$ and the east Atlantic areas $\left(0^{\circ}-30^{\circ} \mathrm{E}\right)$, whereas the AEA pattern was preceded by blocking events occurred in the Urals $\left(60^{\circ}-90^{\circ} \mathrm{E}\right)$ and North American regions $\left(90^{\circ}-\right.$ $\left.120^{\circ} \mathrm{W}\right)$. Similarly, from vortex displacement events we also found two patterns: Aleutian-Intrusion (AI) pattern, where the polar vortex was displaced to the west European and Atlantic areas by the intrusive Aleutian high; North American-Intrusion (NAI) pattern, where the vortex was pushed to the west Eurasian continent by the intrusive high-pressure system from west parts of North America. The AI pattern always corresponded to blocking events occurred in the Pacific basin only, while the NAI pattern was closely related to the blocking over the North American areas. The evidences presented here suggested that different geographical blocking distributions prior to sudden warming events played a significant role in determining the onset and type of the warmings.

Stratospheric anomalous signals were able to propagate downward to the troposphere in strong SSW events, and may spend about $10-15 \mathrm{~d}$ from 10 to $500 \mathrm{hPa}$ level. If the splitting or displacement polar vortex sustained more than one week in a relatively fixed area, the negative geopotential height anomalies would be propagated to the lower layers in the regions corresponding to the location of stratospheric vortex. Therefore, in different warming patterns, stratospheric signals were observed in different areas. Four typical SSW examples for different warming patterns were chosen in this study to investigate the SSW-induced feedback. In the ENA pattern, cold low-pressure centers, derived from splitting vortex, were found in the middle and high latitudes of Eurasian and North American continents, and negative $\mathrm{GH}$ anomalies were propagated downward to $500 \mathrm{hPa}$ level in these areas, leading to apparent cooling effects in the Urals, northwest Europe and north Pacific. In the AEA pattern, most of the stratospheric anomalies were propagated down to the troposphere in the East Asia, resulting in negative temperature anomalies in middle China and north Japan. On the other hand, in the vortex displacement events, most stratospheric signal propagations also occurred in the polar vortex location, and major SSWinduced influences were observed in the northwest Europe, north Atlantic and northeast parts of North American in the AI warming pattern, while in the NAI pattern, stratospheric anomalies were propagated to the middle and west Eurasian continent. Consequently, whether there were stratospheric feedbacks on the lower atmosphere after the sudden warming events depended on the intensity of disturbed polar vortex, and the downward propagation regions were closely related to its durations and positions.

Earlier studies have mostly focused on the separate characteristics and processes of tropospheric blocking high or SSW events, but have neglected the relationship between the two. Taguchi proposed the possibility of statistical connections between these two systems [19], and Martius et al. [20] analyzed them by classifying the SSW into two types, vortex splitting and vortex displacement events. Using statistical and dynamical analyses, we further investigated the variation features of polar vortex and obtained four distribution patterns, which we can ascribe to different activities of blocking high. The active regions of blocking not only occurred in the Pacific and Atlantic basins, proposed by Martius et al. [20], but also in Urals and North American continent, where there were also blocking activities which were going to disturb the stratospheric polar vortex, leading to sudden warming events. According to the researches of warming feedback on lower atmosphere, we found that polar vortex was the critical element to establish the connections between the stratosphere and troposphere, and the blocking high was a driving mechanism to induce the vortex anomalies, thus more detailed and advanced studies should be carried out in the future to investigate the coupled interaction of stratosphere and troposphere through the polar vortex.

This work was supported by the National Basic Research Program of China (2010CB428604), the National Natural Science Foundation for Young Scholars (41205041) and the Postdoctoral Science Foundation of China (2012M510383). The meteorological analysis was kindly provided by National Centers for Environmental Prediction.

1 Andrews D G, Holton J R, Leovy C B. Middle Atmospheric Dynamics. San Diego: Academic Press, 1987

2 Kodera K, Kuroda Y, Pawson S, et al. Stratospheric sudden warming and slowly propagating zonal-mean zonal wind anomalies. J Geophys Res, 2000, 105: 12351-12359

3 Matsuno T. A dynamical model of stratospheric sudden warming. J Atmos Sci, 1971, 28: 1479-1494

4 Baldwin M P, Dunkerton T J. Propagation of the arctic oscillation from the stratosphere to the troposphere. J Geophys Res, 1999, 104: 30937-30946

5 Baldwin M P, Dunkerton T J. Stratospheric harbingers of anomalous weather regimes. Science, 2001, 294: 581-584

6 Yoden S, Yamaga T, Pawson S, et al. A composite analysis of the stratospheric sudden warmings simulated in a perpetual January integration of the Berlin TSM GCM. J Meteorol Soc Jpn, 1999, 77: 431445

7 Julian P R, Labitzke K B. A study of atmospheric energetic during the January-February 1963 stratospheric warming. J Atmos Sci, 1965, 22: 597-610

8 Quiroz R S. The association of stratospheric warmings with tropospheric blocking. J Geophys Res, 1986, 91: 5277-5285

9 Mukougawa H, Sakai H, Hirooka T. High sensitivity to the initial condition for the prediction of stratospheric sudden warming. Geophys Res Lett, 2005, 32: L17806

10 Kodera K, Chiba M. Tropospheric circulation changes associated 
with stratospheric sudden warmings: A case study. J Geophys Res, 1995, 100: 11055-11068

11 Mukougawa H, Hirooka T. Predictability of stratospheric sudden warming: A case study for 1998/99 winter. Mon Weather Rev, 2004, 132: $1764-1776$

12 Thompson D W J, Wallace J M. Regional climate impacts of the northern hemisphere annular mode. Science, 2001, 293: 85-89

13 Manney G L, Krüger K, Sabutis J L, et al. The remarkable 20032004 winter and other recent warm winters in the arctic stratosphere since the late 1990s. J Geophys Res, 2005, 110: D04107

14 Dole R M, Gordon N D. Persistent anomalies of the extratropical northern hemisphere wintertime circulation: Geographical distribution and regional persistence characteristics. Mon Weather Rev, 1983, 111: $1567-1586$
15 Ding Y H. Advanced Synoptic Meteorology (in Chinese). Beijing: China Meteorological Press, 2005. 460-480

16 Tibaldi S, Molteni F. On the operational predictability of blocking. Tellus, 1990, 42: 343-365

17 Schwierz C, Croci-Maspoli M, Davies H C. Perspicacious indicators of atmospheric blocking. Geophys Res Lett, 2004, 31: L06125

$18 \mathrm{Lu} \mathrm{C} \mathrm{H,} \mathrm{Liu} \mathrm{Y,} \mathrm{Liu} \mathrm{C} \mathrm{X.} \mathrm{Middle} \mathrm{atmosphere} \mathrm{response} \mathrm{to} \mathrm{ENSO}$ events in northern hemisphere winter by the whole atmosphere community climate model. Atmos-Ocean, 2011, 49: 98-111

19 Taguchi M. Is there a statistical connection between stratospheric sudden warming and tropospheric blocking events. J Atmos Sci, 2008, 65: $1442-1454$

20 Martius O, Polvani L M, Davies H C. Blocking precursors to stratospheric sudden warming events. Geophys Res Lett, 2009, 36: L14806

Open Access This article is distributed under the terms of the Creative Commons Attribution License which permits any use, distribution, and reproduction in any medium, provided the original author(s) and source are credited. 